\title{
Qualidade do leite em diferentes sistemas de produção, ano e estação climática*
}

\section{Milk quality in different production systems, year and weather seasons}

\author{
Marceli Pazini Milani, ${ }^{* *}$ Diego Prado de Vargas, ${ }^{* * *}$ Renius de Oliveira Mello, ${ }^{* * *}$ Maria de Fátima Barros Leal Nörnberg, ${ }^{* * *}$ \\ José Laerte Nörnberg***
}

\begin{abstract}
Resumo
Objetivou-se avaliar a qualidade do leite produzido sob distintos níveis tecnológicos, durante três anos nas quatro estações climáticas, na região sul do Brasil. Os parâmetros de qualidade do leite avaliados foram: gordura, proteína, lactose, sólidos totais, contagem de células somáticas e contagem bacteriana total, oriundas de 346 propriedades classificadas em três sistemas de produção (não especializado, semi especializado, especializado). Os dados foram analisados por modelo misto com medida repetida no tempo, tendo como efeito fixo o sistema de produção, ano e estação, e efeito aleatório a propriedade designada em cada sistema de produção. Observou-se percentual elevado de amostras em desacordo com a Instrução Normativa Brasileira ${ }^{\circ}$ $62 / 2011$. O sistema de produção afetou a contagem bacteriana total e o teor de gordura, com valores superiores para ambas no sistema não especializado. Todas as variáveis foram influenciadas pela estação do ano, sendo que no outono o leite apresentou percentuais superiores de gordura, proteína, sólidos totais e inferior de CBT. O teor de lactose foi influenciada pelo sistema de produção e pela estação do ano, demonstrando a influência dos fatores estudados na qualidade do leite produzido.
\end{abstract}

Palavras-chave: composição química, nível tecnológico, variação sazonal.

\section{Abstract}

This study aimed evaluate the quality of milk yield under different technological levels, for three years in the four seasons, in southern Brazil. The quality parameter of milk were evaluated: fat, protein, lactose, total solids, somatic cell count and total bacterial count, collected from 346 dairy farms classified in three levels of the production systems (specialized, partially specializes and nonspecialized). Data were analyzed by mixed model with repeated measures in time, with the fixed effect production systems, years and seasons, and random effect property designated in each production system. We observed a high percentage of samples in disagreement with Federal Normative Instruction 62/2011 (IN 62), created to establish quality parameters for milk in the country. The production system affected the total bacterial count and fat content, with higher values for both in the nonspecialized system. All variables were influenced by the season, and in the fall the milk had a higher percentage of fat, protein, total solids and lower CBT. The lactose content was influenced by production systema and the season, demonstrating the influence of the factors studied in the quality of milk yield.

Keywords: chemical composition, technological level, seasonal variation.

\section{Introdução}

O Brasil é o quarto maior produtor de leite do mundo, dados oficiais mais recentes do Instituto Brasileiro de Geografia e Estatística (IBGE) registram 34,3 bilhões de litros de leite captados no país em 2013. O Estado do Rio Grande do Sul é o segundo maior produtor nacional, com 4,5 bilhões de litros de leite, sendo a mesorregião Noroeste a maior produtora deste Estado (IBGE, 2015). Nos últimos anos, a taxa anual de crescimento da produção nacional de leite, esteve em torno de 4\% (Embrapa, 2011), com crescimento de 6\% em 2013, e estimativa de 4,8\% para 2014 (IBGE, 2015). A atividade caracterizada pela grande heterogeneidade, tanto das técnicas de produção, quando do rebanho e perfil de produtores.Dentre os principais entraves para o setor estão a baixa eficiência produtiva e qualidade do leite, alicerçadas na falta de investimento e assistência técnica.

A demanda mundial de lácteos tem se elevado consideravelmente nos últimos anos. Os últimos dados da Organização das Nações Unidas para Alimentação e Agricultura (FAO) mostram que a produção mundial de leite cresceu mais de $50 \%$ nas últimas três décadas (CEPEA, 2014). Estima-se que na próxima década, o consumo global de lácteos deve ultrapassar a oferta disponível pela primeira vez na história com uma expectativa de expansão de 36\% até 2024 (Tetra Pak, 2014).Pelas características conjunturais do país, há uma expectativa que o Brasil possa atender esse mercado em expansão. Entretanto, para que a abertura do mercado externo aos produtos lácteos nacionais possa efetivamente ocorrer, dentre outros fatores, faz-se necessário melhoria na sanidade e normatização do leite e seus derivados.

\footnotetext{
${ }^{*}$ Recebido em 31 de março de 2015 e aceito em 10 de outubro de 2016.

**Universidade Federal de Santa Maria; Departamento de Ciência e Tecnologia dos Alimentos (DTCA); Santa Maria; RS; Brasil.

${ }^{* * *}$ Universidade Federal de Santa Maria; Departamento de Ciência e Tecnologia dos Alimentos (DTCA); Santa Maria; RS; Brasil.

Autor para correspondência: marci_vet@hotmail.com.
} 
Almejando atingir o padrão de qualidade do leite exigido internacionalmente e, consequentemente, aumentar as exportações, o governo brasileiro instituiu a Instrução Normativa $n^{\circ} 51$ de setembro de 2002 (BRASIL, 2002), a qual não atingiu plenamente seus objetivos, sendo substituída pela Instrução Normativa $n^{\circ} 62$ de dezembro de 2011 (BRASIL, 2011), que estabelece, dentre outras normas, os novos parâmetros e prazos para contagem bacteriana total e contagem de células somáticas nas diferentes regiões do país, escalonados até o ano de 2016.

O estudo dos fatores que influenciam na composição química e qualidade higiênico-sanitária do leite é de fundamental importância, tendo em vista a heterogeneidade do sistema produtivo, e a necessidade de padronização da matériaprima. Dentre esses fatores pode-se destacar a mudança na alimentação das vacas (Kelly et al., 1998; Elgersma et al. 2004), a qual pode variar entre sistemas produtivos e estações do ano, levando a prováveis mudanças na composição química do leite. $\mathrm{O}$ que também pode ocorrer na qualidade higiênicosanitária do leite, a qual sofre influencia do manejo adotado, que é influenciado pelo sistema produtivo. O estudo desses fatores servirá de subsídios para o desenvolvimento de programas de melhoria e serviços de assistência técnica.

Objetivou-se avaliar a qualidade do leite produzido em função dos diferentes sistemas de produção adotados, juntamente com o efeito do ano (três anos consecutivos) e da estação climática (primavera, verão, outono e inverno), suas interações e comparar com os padrões preconizados pela Instrução Normativa $n^{\circ} 62$ de dezembro de 2011.

\section{Material e métodos}

As informações utilizadas no estudo foram provenientes da base de dados de uma empresa e uma cooperativa, que juntas adquirem o leite produzido em 326 unidades produtores de leite (UPL), localizadas na Mesorregião Noroeste do Rio Grande do Sul, distribuídas nas Microrregiões de Frederico Westphalen e Carazinho. Segundo a classificação Köppen, o clima da região é do tipo Cfa (subtropical úmido), com chuvas distribuídas durante todo o ano e temperatura média do mês mais quente acima de $22^{\circ} \mathrm{C}$ (Moreno, 1961). Segundo o zoneamento climático para a cultura de forrageiras de clima tropical e subtropical (Embrapa, 1994), a região é classificada como tolerada (nove meses com temperatura média das mínimas igual ou superior a $10^{\circ} \mathrm{C}$ ) e, pelo Sistema Brasileiro de Classificação de Solos (Santos et al., 2006), o solo é tipo latossolo vermelho distrófico típico (Unidade de Mapeamento de Passo Fundo).

Visitas mensais foram realizadas as 326 UPLs, quando foram coletadas informações que permitiram classificá-las em três sistemas de produção distintos: especializado $(n=38)$, semiespecializado $(n=78)$ e não especializado $(n=210)$, conforme os critérios abaixo:

- Sistema especializado (ES): produção acima de 18 L/vaca/ dia, ordenha canalizada ou semi canalizada, conservação do leite em resfriador a granel, rebanho com animais predominantemente da raça Holandês. Alimentação a base de silagem de milho, concentrado a base de milho e farelo de soja, ofertado acima de $4 \mathrm{~kg} / \mathrm{vaca} /$ dia e pastagem cultivada.

- Sistema semi especializado (SE): produção entre 10 e 18 L/vaca/dia, ordenha balde ao pé, conservação do leite em resfriador de imersão ou outro equipamento que não seja resfriador a granel. Animais sem caracterização racial, com predomínio de taurinos, alimentação a base de campo nativo e pastagem cultivada em algumas épocas do ano, suplementação com concentrado a base de milho, ofertado abaixo de $4 \mathrm{~kg} / \mathrm{vaca} / \mathrm{dia}$.

- Sistema não especializado (NE): produção inferior a 10 L/vaca/dia, ordenha manual, conservação do leite em equipamento não recomendado pela legislação, rebanho sem caracterização racial, com predomínio do cruzamento entre zebuínos e taurinos, alimentação a base de campo nativo.

A coleta foi realizada diretamente do equipamento onde o leite estava acondicionado nas UPLs, imediatamente após a homogeneização, sendo mantidas em refrigeração $\left(7^{\circ} \mathrm{C}\right)$ e conservadas com bronopol, para análise da composição química (gordura, proteína, lactose e sólidos totais) e CCS (contagem de células somáticas) e azidiol para CBT (contagem bacteriana total). A determinação da composição química foi realizada por espectrometria de radiação infravermelha, utilizando equipamento Bentley 2000 (Bentleylnstruments, EUA), a contagem de células somáticas e bacteriana total por citometria de flluxo utilizando respectivamente, os equipamentos Somacount 300 e Bactocount IBC (Bentleylnstruments, EUA).

O banco de dados bruto continha 4.341 observações provenientes das 326 UPLs, correspondendo a todas as análises realizadas pela empresa e cooperativa no período de três anos consecutivos, sendo aleatória a escolha das UPLs que proviam as amostras mensalmente, resultando num valor médio de 4,4 amostras/UPL/ano. Durante a edição dos dados foram eliminadas as amostras com teores de gordura abaixo de $2 \%$ e acima de $6 \%$ por serem considerados provenientes de erros de amostragem e/ou analítico, bem como calculada a média para cada parâmetro de qualidade do leite de cada UPL nos três meses que compõem cada estação do ano, reduzindo assim para 1.946 observações de gordura, proteína, lactose e sólidos totais; 1944 para CCS e 1.733 para CBT. Em função da CCS e CBT não apresentarem normalidade residual, as mesmas foram transformadas, respectivamente, para as funções logarítmica natural e raiz quadrada.

Os dados foram analisados como medida repetida no tempo por meio de modelo linear misto, com estrutura paramétrica especial nas matrizes de covariâncias, conforme modelo estatístico:

$$
\mathrm{Yijkl}=\mu+\alpha_{\mathrm{i}}+\mathrm{b}_{\mathrm{ij}}+\gamma_{\mathrm{k}}+(\alpha \gamma)_{\mathrm{ik}}+\tau_{\mathrm{l}}+(\alpha \tau)_{\mathrm{il}}+(\gamma \tau)_{\mathrm{kl}}+\varepsilon_{\mathrm{ijkl}}
$$

em que $Y_{\mathrm{ijkl}}$ é o valor observado pela l-ésima estação, k-ésimo ano e j-ésima unidade produtora de leite do i-ésimo sistema de produção; $\mu$ é a média geral da variável resposta; $\alpha_{i}$ é o efeito fixo do i-ésimo sistema de produção; $b_{i j}$ é o efeito aleatório da j-ésima UPL designada ao i-ésimo sistema de produção; $\bigvee_{k}$ é o efeito fixo do k-ésimo ano; ( $\alpha$ y $)_{\mathrm{ik}}$ é o efeito fixo dainteração do k-ésimo ano com o i-ésimo sistema de produção; тé o efeito fixo da l-ésimaestação do ano; $(\alpha \mathrm{T})_{\mathrm{il}}$ é o efeito fixo da interação entre a l-ésima estação do ano e o i-ésimosistema de produção; ( $\left.\gamma^{\top}\right)$ kl é o efeito fixo da interação da l-ésima estação com o k-ésimo ano; e $\varepsilon_{i \mathrm{jkl}}$ é o erro aleatório associado a obserçãoijkl. Devidoa obtenção de várias medidas na mesma unidade experimental (bij), assumiu-se uma estrutura de medidas repetidas para os resíduos, ou seja, pressupostos que $\varepsilon_{\mathrm{ijkl}} \sim N(0 ; \Sigma)$, em que $\Sigma$ 
representa a matriz de (co)variância residual do tipo auto regressiva heterogênea de primeira ordem - ARH (1) - para os teores de gordura, proteína, lactose e sólidos totais; e auto regressiva de primeira ordem - AR (1) - para CCS e CBT. Contudo, para cada variável dependente, a UPL foi submetida a outras estruturas de (co)variância: componentes de variância (VC), simetria composta (CS), simetria composta heterogênea de primeira ordem $(\mathrm{ARH}(1))$, média móvel auto regressiva de primeira ordem $(\operatorname{ARMA}(1,1))$, Toeplitz (TOEP). A escolha da estrutura de (co)variância baseou-se no modelo que minimizasse os valores do critério de informação Bayesiano de Schwarz (BIC - Schwarz'sBayesianCriterion), calculado na forma de -2l + dlogn (Schwarz, 1978).

Os componentes de (co)variância e as soluções para os efeitos fixos foram estimados pelo método da Máxima Verossimilhança Restrita (REML RestrictedMaximumLikelihood), e o número de graus de liberdade do denominador para o teste $\mathrm{F}$ foi calculado pelo método de Kenward-Rogers, empregando o procedimento MIXED (Littel et al., 2006). As medidas foram estimadas com o comando LSMEANS (Least Square Means) e comparadas com o comando ESTIMATE pela diferença mínima significativa - DMS (LSD - LeastSignificantDifference) ao nível de 5\% de significância.

As análises estatísticas foram realizadas no software SAS ${ }^{\circledR}$ System for Windows 9.0 .

\section{Resultados e discussão}

Os resultados das análises de leite comparadas com os padrões exigidos pela legislação brasileira (Tabela 1), mostram elevado percentual de amostras fora do preconizado, principalmente para a qualidade higiênico-sanitária do leite. No total das amostras analisadas, esse porcentual fica em $80,40 \%$ para CBT e $49,58 \%$ para CCS.

Nero et al. (2005) avaliaram quatro áreas de quatro estados produtores de leite no Brasil e observaram 48,6\% das amostras com contagem bacteriana acima de $750.000 / \mathrm{mL}$. Os porcentuais observados no presente estudo são ainda maiores e preocupam o setor lácteo, pois expõe a existência de falhas produtivas no que tange a ordenha, higienização e armazenamento da matériaprima, mesmo nas UPLs classificadas como especializadas.

Não foi observado interação entre os efeitos do sistema produtivo e da estação do ano para as variáveis estudadas (Tabela 2), ou seja, as variações de qualidade observada entre os diferentes sistemas produtivos, não tem influência da estação do ano e vice-versa. Ambos os fatores interferem na qualidade do leite de forma sistemática, ou seja, a estação do ano teve o mesmo impacto sobre as variáveis em estudo, independente do sistema de produção adotado, sendo a recíproca verdadeira.

Além disso, observa-se que o sistema de produção influencia significativamente a CBT e o teor de gordura do leite (Tabela 3).
Tabela 1: Porcentagem de amostras de leite em desacordo com os padrões propostos pela Instrução Normativa 62/2011, EM diferentes sistema de produção

\begin{tabular}{lcccc}
\hline \multirow{2}{*}{ Sistema de produção } & CBT $^{1}$ & CCS $^{2}$ & Gordura $^{3}$ & Proteína $^{4}$ \\
\cline { 2 - 5 } & \multicolumn{4}{c}{$\%$} \\
\hline Especializado & 54,00 & 53,14 & 4,60 & 6,11 \\
Semi especializado & 80,95 & 47,30 & 4,90 & 11,24 \\
Não especializado & 89,71 & 50,10 & 11,82 & 18,34 \\
\hline
\end{tabular}

${ }^{1} \mathrm{CBT}$ : Contagem bacteriana total (limite máximo de $600.000 \mathrm{UFC} / \mathrm{mL}$ de leite); ${ }^{2} \mathrm{CCS}$ : Contagem de células somáticas (limite máximo de 600.000 células $/ \mathrm{mL}$ de leite); ${ }^{3}$ Limite mínimo 3,0 (g/100 g); ${ }^{4}$ Limite mínimo 2,9(g/100 g). do leite para os efeitos fixos e suas interações

\begin{tabular}{lcccccc}
\hline \multirow{2}{*}{ Efeito fixo } & \multicolumn{7}{c}{ Pr>F } \\
\cline { 2 - 7 } & Gordura & Proteína & Lactose & ST $^{1}$ & CCS $^{2}$ & CBT $^{3}$ \\
\hline Sistema de produção & 0,0214 & 0,2850 & 0,0227 & 0,7656 & 0,9816 & $<0,0001$ \\
Ano & 0,0002 & 0,0151 & 0,1764 & 0,0192 & $<0,0001$ & 0,0254 \\
Estação do ano & $<0,0001$ & $<0,0001$ & $<0,0001$ & $<0,0001$ & 0,0095 & 0,0166 \\
Sistema de produção x ano & 0,3976 & 0,1673 & 0,0045 & 0,0228 & 0,7309 & 0,3055 \\
Sistema x Estação do ano & 0,8401 & 0,3812 & 0,7308 & 0,5933 & 0,9717 & 0,4207 \\
Ano x Estação do ano & 0,0244 & $<0,0001$ & 0,0614 & $<0,0001$ & 0,0104 & 0,1551 \\
\hline
\end{tabular}

Tabela 3: Médias ajustadas do teor de gordura do leite e contagem bacteriana total (CBT) em diferentes sistemas de produção

\begin{tabular}{|c|c|c|c|}
\hline \multirow{2}{*}{ Variável } & \multicolumn{3}{|c|}{ Sistema de produção } \\
\hline & Especializado & Semi especializado & Não especializado \\
\hline Gordura, \%, ( \pm EP) & $3,59^{\mathrm{b}}( \pm 0,05)$ & $3,72^{\mathrm{ab}}( \pm 0,04)$ & $3,76^{\mathrm{a}}( \pm 0,02)$ \\
\hline $\mathrm{CBT}^{\star *}, \mathrm{UFC} / \mathrm{mL}( \pm \mathrm{EP})$ & $1.469,63^{\mathrm{c}}( \pm 10,67)$ & $3.493,99^{b}( \pm 5,14)$ & $5.045,54^{\mathrm{a}}( \pm 2,64)$ \\
\hline
\end{tabular}

*Letras diferentes na mesma linha, diferem entre si $(\mathrm{P}<0,05)$.

${ }^{*} \mathrm{CBT}$ : Contagem bacteriana total (x $\left.1000 \mathrm{UFC} / \mathrm{mL}\right)$

Tendo em vista as técnicas de manejo de ordenha adotadas, baixo investimento em infraestrutura e condições de armazenamento do leite na propriedade, as altas contagens para CBT observadas, principalmente, nos sistemas não especializado e semi especializado eram esperadas. Entretanto o valor médio de $1.469,63$ de UFC/mL para o leite produzido nas UPLs especializadas mostra que, mesmo as propriedades com maior nível tecnológico, ainda tem dificuldade em obter um produto de melhor qualidade higiênico sanitária.

O teor de gordura do leite é maior em propriedades que utilizam o sistema de produção não especializado quando comparadas com as especializadas, tal situação está relacionada com o volume de produção de leite por animal, o padrão racial dos rebanhos e o sistema de alimentação adotado.

Também a genética poderia ter uma forte influência sobre a variável gordura, animais da raça Holandês, predominantes no sistema especializado, produzem leite com porcentagem de gordura inferior às demais raças. Isso está relacionado, 
dentre outros fatores, com a maior produção total de leite por vacas Holandês em comparação com animais de raça não definida ou cruzas com zebuínos, presentes no sistema não especializado, que, portanto, tem uma produção diária menor de leite, mas com um percentual de gordura superior, devido a concentração dos nutrientes.

O teor de gordura também sofreu influência da estação do ano (Tabela 4), sendo que, o leite produzido no outono apresentou maiores percentuais desse constituinte. Tal resultado justificase por dois motivos principais: a menor produção de leite nessa estação (Tabela 5) e as diferenças de quantidade e qualidade da alimentação recebida pelos animais nas estações do ano. A Tabela 5 foi elaborada a partir do volume total de leite produzido pelo rebanho, o mesmo reflete a produção individual das vacas, tendo em vista que não houve diferença estatística entre o número de vacas em ordenha nas diferentes estações do ano.

Hecket al. (2009) constataram a variabilidade no teor de gordura do leite em função da estação do ano, e associaram o efeito ao tipo de planta forrageira oferecida aos animais. Ou seja, a influência da estação do ano na composição química do leite está relacionada com a nutrição da vaca, mais especificamente, com a pastagem, tanto em quantidade como na qualidade das espécies forrageiras ofertadas. No outono, além da menor oferta de pastagens devido ao vazio forrageiro outonal, tem-se uma qualidade bromatológica inferior (menor presença de carboidratos não fibrosos e maior teor de fibra em detergente neutro) em relação as forrageiras que se desenvolvem nas demais estações, principalmente no inverno da Região Sul do Brasil, refletindo assim em menor produção de leite e aumento do percentual de gordura.

O leite produzido na primavera apresentou o menor teor de gordura (Tabela 4), porém o inverno foi a estação que teve a maior produção de leite (Tabela 5). Esse fato justifica, em parte, a redução percentual da gordura por efeito de diluição. Associado a isso, a oferta de gramíneas temperadas (principalmente, aveia preta e azevém) durante este período predispõe a formação de isômeros do CLA (ácido linoleico conjugado) no ambiente ruminal, os quais estão ligados à diminuição da gordura do leite (Harvatine e Allen, 2006).

Os menores valores de proteína foram observados na primavera e maiores no outono (Tabela 4), seguindo uma tendência inversa a produção de leite (Tabela 5). Essa variação do teor de proteína
Tabela 5: Média da produção mensal de leite nas diferentes estações climáticas

\begin{tabular}{ccccc}
\hline \multirow{2}{*}{ Variável } & \multicolumn{4}{c}{ Estação do ano } \\
\cline { 2 - 5 } & Primavera & Verão & Outono & Inverno \\
\hline L/UPL $^{* *} /$ mês & $3921,36^{a}$ & $3640,76^{\text {ab }}$ & $3184,76^{\text {b }}$ & $4200,64^{a}$ \\
\hline
\end{tabular}

*Letras diferentes na mesma linha, diferem pelo teste Tukey $(P<0,05)$ ${ }^{*} \mathrm{~L} / \mathrm{UPL}=$ Litros por Unidade Produtora de Leite

acompanhando a produção de leite também foi relatada por Teixeira et al. (2003). Tal situação se justifica por a proteína estar entre os componentes do leite com menor variação em função da dieta, não sofrendo influência da melhor qualidade nutricional das gramíneas temperadas, com maior teor de proteína bruta e carboidratos não fibrosos. $\mathrm{O}$ aumento da eficiência energética para a síntese do leite, que levou ao aumento do volume produzido, não foi acompanhado pelo aumento da extração de aminoácidos pela glândula mamária, resultando na diminuição do conteúdo de proteína do leite observados no inverno e, principalmente, na primavera.

O teor de sólidos totais do leite não diferiu entre os sistemas produtivos adotados (Tabela 6 ). Tal resultado se justifica por essa variável ser composta pela soma de todos os componentes do 
leite, exceto a água. Assim, o resultado encontrado no segundo e terceiro ano era esperado, uma vez que, como visto na Tabela 2 , lactose e gordura variaram inversamente entre os sistemas de produção, enquanto a proteína não diferiu entre eles.

A lactose e sólidos totais tiveram interação entre o sistema de produção e o ano em estudo (Tabelas 2 e 6), ambas apresentaram comportamento diferente entre os sistemas apenas no primeiro ano, não diferindo no segundo o terceiro. Essa variação nos anos em estudo não é explicada pelos fatores pesquisados neste trabalho. As propriedades pertencentes ao sistema especializado produziram o leite com teores superiores de lactose nos três anos de coleta, não diferindo estatisticamente do primeiro ano em relação as não especializadas (Tabela 6).

Tabela 6: Médias ajustadas dos teores de lactose e sólidos totais do leite, em função dos efeitos fixos do sistema de produção e ano

\begin{tabular}{|c|c|c|c|c|}
\hline \multirow{3}{*}{ Ano } & \multicolumn{3}{|c|}{ Sistema de produção } & \multirow{3}{*}{ Média geral } \\
\hline & Especializado & $\begin{array}{c}\text { Semi } \\
\text { especializado }\end{array}$ & $\begin{array}{c}\text { Não } \\
\text { especializado }\end{array}$ & \\
\hline & \multicolumn{3}{|c|}{ Lactose, \% } & \\
\hline $1^{\circ}$ & $4,33^{\mathrm{Aa}} \pm 0,04$ & $4,22^{\mathrm{Bb}} \pm 0,03$ & $4,29^{A a} \pm 0,02$ & $4,28 \pm 0,02$ \\
\hline $2^{\circ}$ & $4,36^{\mathrm{Aa}} \pm 0,03$ & $4,31^{\mathrm{Aab}} \pm 0,02$ & $4,28^{\mathrm{Ab}} \pm 0,01$ & $4,31 \pm 0,01$ \\
\hline $3^{\circ}$ & $4,38^{\mathrm{Aa}} \pm 0,03$ & $4,31^{\mathrm{Aa}} \pm 0,02$ & $4,26^{\mathrm{Ab}} \pm 0,01$ & $4,32 \pm 0,01$ \\
\hline Média geral & $4,36 \pm 0,03$ & $4,28 \pm 0,02$ & $4,28 \pm 0,01$ & \\
\hline \multicolumn{5}{|c|}{ Sólidos totais, \% } \\
\hline $1^{\circ}$ & $11,94^{\mathrm{Aab}} \pm 0,11$ & $11,87^{\mathrm{Bb}} \pm 0,08$ & $12,08^{\mathrm{Aa}} \pm 0,07$ & $11,97 \pm 0,05$ \\
\hline $2^{\circ}$ & $12,00^{A a} \pm 0,09$ & $12,18^{\mathrm{Aa}} \pm 0,06$ & $12,09^{A a} \pm 0,05$ & $12,09 \pm 0,04$ \\
\hline $3^{\circ}$ & $12,11^{\mathrm{Aa}} \pm 0,10$ & $12,18^{\mathrm{Aa}} \pm 0,07$ & $12,08^{\mathrm{Aa}} \pm 0,04$ & $12,12 \pm 0,04$ \\
\hline Média geral & $12,02 \pm 0,08$ & $12,08 \pm 0,04$ & $12,08 \pm 0,04$ & \\
\hline
\end{tabular}

${ }^{*}$ Médias seguidas por letras maiúsculas distintas na mesma coluna e por letras minúsculas distintas na mesma linha diferem $(P<0,05)$, pela diferença mínima significativa.

Por ser o regulador osmótico no alvéolo mamário, a lactose é o constituinte de menor variação no leite, assim sua variação entre os sistemas de produção não era esperada. Segundo Sutton (1989), a concentração de lactose não pode ser alterada por modificações na dieta, salvo em condições de subnutrição. O manejo alimentar adotado nos sistemas de produção semi e não especializado expôs os animais a quadros de subnutrição, refletindo numa redução do teor de lactose (Tabela 6). A mesma situação ocorreu no outono (Tabela 7), estação caracterizada pela baixa oferta e baixo valor nutricional das pastagens, e que apresentou o leite com menor teor de lactose em comparação as demais estações do ano.

Com relação aos parâmetros higiênicos sanitários do leite, a contagem bacteriana total (CBT) apresentou valores significativamente superiores no inverno e inferior no outono (Tabela 7), enquanto a contagem de células somáticas (CCS) foi superior no verão (Tabela 4). Trabalhos ao longo dos anos vêm relacionando o estresse térmico, característico do verão, com o aumento da CCS do leite e a ocorrência de mastite,pois aumenta a suscetibilidade a infecções, bem como o número de patógenos aos quais os animais estão expostos.

Resultado semelhante a esta pesquisa foram encontrados por Roma et al. (2009), quando avaliaram o efeito da estação do ano sobre a composição do leite, CCS e CBT, concluindo que o outono é a estação de melhor qualidade do leite, contemplando elevação do teor de gordura, proteína e diminuição da CBT, e que no verão tem-se um aumento significativo da CCS.

\section{Conclusões}

O sistema de produção tem influência sobre o teor de gordura, lactose e contagem bacteriana. O leite produzido no sistema não especializado apresenta contagem bacteriana total mais elevada, com teor de gordura superior e lactose inferior aos demais. $A$ estação do ano influencia na qualidade e quantidade do leite produzido, tendo o outono menor produção e melhor qualidade, com valores superiores de gordura, proteína e sólidos totais e menor contagem bacteriana total. O verão é a estação do ano com maior predisposição a mastite, tendo uma contagem de células somáticas superior as outras estações. Conclui-se que o leite produzido neste período está fora dos padrões preconizados pela Instrução Normativa $n^{\circ} 62$ de dezembro de 2011.

Tabela 7: Médias ajustadas do teor de lactose e contagem bacteriana total do leite para diferentes estações do ano

\begin{tabular}{lcccc}
\hline \multirow{2}{*}{ Variável } & \multicolumn{4}{c}{ Estação do ano } \\
\cline { 2 - 5 } & Primavera & Verão & Outono & Inverno \\
\hline Lactose, \% ( \pm EP) & $4,33^{\mathrm{b}}( \pm 0,01)$ & $4,27^{\mathrm{c}}( \pm 0,02)$ & $4,22^{\mathrm{d}}( \pm 0,02)$ & $4,39^{\mathrm{a}}( \pm 0,01)$ \\
& $3.093,28^{\mathrm{ab}}$ & $3.182,91^{\mathrm{ab}}$ & $2.897,19^{\mathrm{b}}$ & $3.454,66^{\mathrm{a}}$ \\
$\mathrm{CBT}^{* *}$ & $( \pm 3,26)$ & $( \pm 3,80)$ & $( \pm 3,02)$ & $( \pm 2,98)$ \\
\hline
\end{tabular}

*Letras diferentes na mesma linha, diferem entre $\mathrm{si}(\mathrm{P}<0,05)$.

${ }^{* *}$ Contagem bacteriana total (x $\left.1000 \mathrm{UFC} / \mathrm{mL}\right)( \pm \mathrm{EP})$ 


\section{Referências}

BRASIL. Ministério da Agricultura, Pecuária e Abastecimento. Instrução Normativa $n^{\circ}$ 51, de 18 de setembro de 2002, Brasília, Disponível em: http://portal.mda.gov.br/o/776834. Acesso em: 18 set. 2011.

BRASIL. Ministério da Agricultura, Pecuária e Abastecimento. Instrução Normativa no 62, de 30 de dezembro de 2011, Brasília, Disponível em: http://www.in.gov.br/visualiza/index.jsp?data=30/1 2/2011\&jornal=1\&pagina=6\&totalArquios=160. Acesso em: 23 abr. 2013.

CEPEA, Centro de Estudos Avançados em Economia Aplicada, Boletim do Leite, ESALQ/USP, n²26, Ano 20, fev., 2014.

ELGERSMA, A.; ELLEN, G.; VAN DER HORST, H.; MUUSE, B.G.; BOER, H.; TAMMINGA, S. Comparasion of the fatty acid composition of fresh and ensiled perennial ryegrass (Lolium perene L.), affected by cultivar and regrowth interval. Animal Feed Science and Technology, v.108, p.191-205, 2003.

EMBRAPA-CNPT. Zoneamento climático para a cultura de forrageiras de clima tropical e subtropical. In: Macrozoneamento agroecológico e econômico - Estado do Rio Grande do Sul - v.2. Porto Alegre: Secretaria da Agricultura, 1994. 33p.

EMBRAPA-CNPGL. Diagnóstico da Pecuária de Leite nacional. 2011. Disponível em: http://www.cnpgl.embrapa.br/nova/Plano_ Pecuario_2012.pdf. Acessoem: 28 abr. 2013.

HARVATINE, K.J.; ALLEN, M.S. Effects of fatty acid supplements on ruminal and total tract nutrient digestion in lactating dairy cows. Journal of Dairy Science, v.89, p.1092-1103, 2006.

HECK, J.M.L.; van VALENBERG, H.J.F.; DIJKSTRA, J.; van HOOIJDONK, A.C.M. Seasonal variation in the Dutch bovine raw milk composition. Journal of Dairy Science, v.92, p.4745-4755, 2009.

IBGE, Instituto Brasileiro de Geografia e Estatística. Disponível em: http://www.sidra.ibge.gov.br/bda/pecua/default.asp?t=3\&z=t $\& o=24 \& u 1=1 \& u 2=1 \& u 4=1 \& u=1 \& u 6=1 \& u 7=1 \& u 3=34$. Acesso em 28 abr. 2013.
IBGE, Instituto Brasileiro de Geografia e Estatística. Disponível em: http://www.sidra.ibge.gov.br/bda/pecua/default.asp?t=3\&z=t $\& o=24 \& u 1=1 \& u 2=1 \& u 4=1 \& u=1 \& u 6=1 \& u 7=1 \& u 3=34$. Acesso em 28 abr. 2013.

IBGE, Instituto Brasileiro de Geografia e Estatística. Disponível em: http://www.ibge.gov.br/home/estatistica/indicadores/ agropecuaria/producaoagropecuaria/. Acesso em 10 mar. 2015.

KELLY, M.L.; KOLVER, E.S.; BAUMAN, D.E.; VAN AMBURGH, M.W.; MULLER, L.D. Effect of intake of pasture on concentrations of conjugated linoleic acid in milk lactating cows. Journal of Dairy Science, v.81, p.1630-1636, 1998.

NERO, L.A.; MATTOS, M.R.; BELOTI, V.; BARROS, M.A.F.; PINTO, J.P.A.N.; ANDRADE, N.J.; SILVA, W.P.; FRANCO, B.D.G.M. Leite cru de quatro regiões leiteiras brasileiras: perspectivas de atendimento dos requisitos microbiológicos estabelecidos pela Instrução Normativa 51. Ciência e Tecnologia de Alimentos, v. 25, p.191-195, 2005.

ONU, Organização das Nações Unidas. Os preços elevados dos alimentos e a segurança alimentar: ameaças e oportunidades. Disponível em: http://www.fao.org/sof/sofi/index_es.htm.Acesso em: 20 out. 2008.

ROMA JR, L.C.; MONTOYA, J.F.G.; MARTINS, T.T.; CASSOLI, L.D.; MACHADO, P.F.Sazonalidade do teor de proteína e outros componentes do leite e sua relação com programa de pagamento por qualidade. Arquivo Brasileiro de Medicina Veterinária e Zootecnia, v.61, p.1411-1418, 2009.

SANTOS, H.G.; JACOMINE, P.K.T.; ANJOS, J.L.C.; OLIVEIRA V.A.; OLIVEIRA, J.B.; COELHO, M.R.; LUMBRERAS, J.F.; CUNHA, T.J.F. Sistema brasileiro de classificação de solos. 2. ed. Rio de Janeiro: Embrapa Solos, 2006. 306 p.

SUTTON, J.D. Altering milk composition by feeding.Journal of Dairy Science, v.72, p.2801-2814, 1989.

TEIXEIRA, N.M.; FREITAS, A.F.; BARRA, R.B. Influência de fatores de meio ambiente na variação mensal da composição e contagem de células somáticas do leite em rebanhos no Estado de Minas Gerais. Arquivo Brasileiro de Medicina Veterinária e Zootecnia, Belo Horizonte, v.55, 2003.

TETRA PAK, Consumo global de lácteos deve crescer $36 \%$ até 2024, Tetra Pak Dairy Index 2014, Disponível em: http:// www.tetrapak.com/br/Pages/tetra-pak-dairy-index-rising-globaldemand-requires-careful-balancing-act.aspx. Acesso em 12 fev. 2015. 